\title{
GCU
}

Glasgow Caledonian

University

University for the Common Good

\section{Power balance and control of transmission lines using static series compensator}

Suliman, Mohammed Y.; Farrag, M. Emad

Published in:

2018 53rd International Universities Power Engineering Conference (UPEC)

DOI:

10.1109/UPEC.2018.8541894

Publication date:

2018

Document Version

Author accepted manuscript

Link to publication in ResearchOnline

Citation for published version (Harvard):

Suliman, MY \& Farrag, ME 2018, Power balance and control of transmission lines using static series compensator. in 2018 53rd International Universities Power Engineering Conference (UPEC). IEEE, pp. 1-5, 2018 53rd International Universities Power Engineering Conference (UPEC), Glasgow, United Kingdom, 4/09/18. https://doi.org/10.1109/UPEC.2018.8541894

\section{General rights}

Copyright and moral rights for the publications made accessible in the public portal are retained by the authors and/or other copyright owners and it is a condition of accessing publications that users recognise and abide by the legal requirements associated with these rights.

Take down policy

If you believe that this document breaches copyright please view our takedown policy at https://edshare.gcu.ac.uk/id/eprint/5179 for details of how to contact us. 


\section{Power Balance and Control of Transmission Lines Using Static Series Compensator}

\author{
Mohammed Y. Suliman \\ College of Technical Engineering \\ Northern Technical University, Mosul, Iraq \\ Mohamed.yahya@ntu.edu.iq
}

\author{
${ }^{1,2}$ M. Emad Farrag \\ ${ }^{1}$ School of Engineering \& Built Environment \\ Glasgow Caledonian University \\ ${ }^{2} F$ aculty of Industrial Education, Helwan University, Egypt \\ Mohamed.Farrag@gcu.ac.uk
}

\begin{abstract}
-
Parallel transmission lines can be utilised for a flow power from a surplus generation area to a load center in a meshed power grid. The distribution current flow in these parallel transmission lines depends on impedance value of the line. The lowest value of impedance will reach the maximum capacity of transmission earlier than other parallel transmission paths and thus determines the maximum transmittable capacity of power, while the other parallel paths are not loaded to maximum capacity. In this paper, a modeling and simulation of parallel transmission lines is presented with series compensator SC for regulating the flow power. The adaptive fuzzy logic control scheme is proposed, Takagi-Sugeno rules type are trained by using off-line in this controller. The results of this study show the ability of the static compensator SC to regulate the power flow in the controlled transmission line between 50 and 100 percent of the rated power flow.
\end{abstract}

Index: FACTS., S.C., $d-q$. theory, park transformation, Sinusoidal Pulse Width Modulation (S.PWM), FLC.

\section{INTRODUCTION}

The control of power flow in the transmission line systems has recently gained increased interest. The difficulties of building the new lines having a high utilisation of existing assetes, and this makes the flexibility of grid increasingly important [1]. The flows of power on the lines depends on line impedance properties. The impedance properties do not always match with the capability of the transmission lines, the actual need or the most economical active power production solution [2]. Due to line impedance, one line might be overloaded and reach the limit of total transmission power, before other parallel paths are utilised [3]. The line current distribution in a parallel transmissions depends on the line impedance. Figure 1 shows the flow of line currents between two nodes in the grid, the two parallel lines with their impedances $\left(Z_{a}\right.$ and $\left.Z_{b}\right)$ where the impedance is:

$z_{i}=r_{i}+x_{i}$

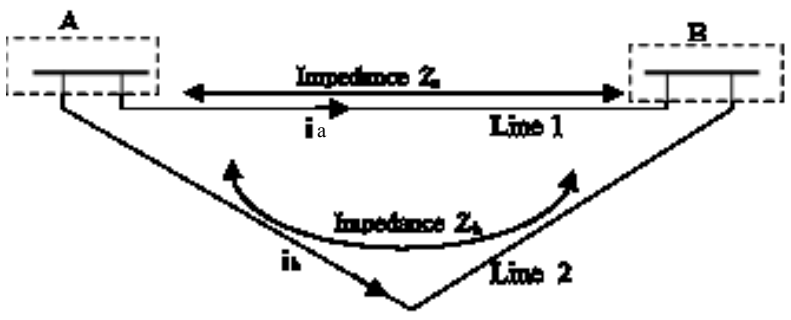

Figure 1 Flow of current from node $A$ to node $B$ determined by line impedances
The line current flow from node A to node B determined by line impedance, the line current distribution in the two parallel branches between $a$ and $b$ :

$i_{a}=\frac{i z_{b}}{z_{a}+z_{b}}$

and :

$i_{b}=\frac{i z_{a}}{z_{a}+z_{b}}$

Where $\mathrm{i}$ is the total line current flow between node $\mathrm{A}$ and node $\mathrm{B}$. The power flow is a function of voltage and current:

$s_{a}=v i_{a}^{*}=v \cdot\left(\frac{i z_{b}}{z_{a}+z_{b}}\right)^{*}$

$s_{b}=v i_{b}^{*}=v \cdot\left(\frac{i z_{a}}{z_{a}+z_{b}}\right)^{*}$

The power distribution in two branches is, as mentioned previously, not always efficient method in loading capability. To make change in the power distribution, a circulating current between two branches can be generated by inserting an additional Static Series Compensator (SC) which consists of voltage source in series with the one branch as shown in figure 2. SC is one of Flexible $\mathrm{AC}$ Transmission System (FACTS) device [4]. The impedance of the line is inductive mainly, therefore the voltage inserted in quadrature with respect to line current. When the amplitude change the reactive power flow also changes. Inserting a voltage out of phase with respect to the line voltage this changes the load angle and also active power flow [5]. The current of regulated line can be given any wanted proportions

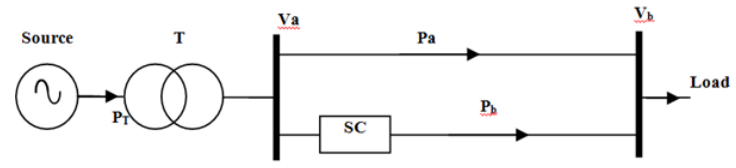

Figure 2 Inserting SC series compensator

\section{MOELLING AND CONTROL OF SERIES COMPENSATOR}

Series compensator $\mathrm{SC}$ is one of the series type of the family of FACTS. SC injects voltage an almost sinusoidal (based on the switching frequency and the configuration of inverter) with control amplitude [6]. SC is equivalent to a capacitive or an inductive reactance connected in series with the line. Voltage Source Inverter (VSI) is the main part of 
SC that is supplied DC from a storage capacitor [7]. Without external DC-link, the series injected voltage has two components: the main component is in quadrature with the line current and emulates capacitive or an inductive reactance in series with the line. The second component is in phase with the line current to supply the losses of the inverter. When the series injected voltage is lagging line current, the injected voltage will emulate as a capacitive reactance in series with the line impedance causing the line current and also the power flow to increase through the line [8]. And when the injected voltage is leading line current, the injected voltage will emulate as an inductive reactance in series with the line impedance causing the line current and also power flow to decrease through the line. SC is more superior than the other series-connected FACTS devices and the advantage of using SC are [9]:

1. Elimination of the bulky passive components - reactors and capacitors.

2. Symmetric capability to work in capacitive operating mode and inductive operating mode.

3. Possibility of exchange real power with the AC network by connecting an energy source on the DC side of the SC.

SC include a (VSI) and a coupling transformer that is used to inject the controlled compensating voltage in series with the transmission line. The votage magnitude and phase angle of injected voltage can be rapidly adjusted by the controls of SC [10]. The SC inserts the series compensating voltage with the impedance of the transmission line with respect to the line current. The power flow through transmission line becomes a parametric function of the inserted voltage(magnitude and phase angle), and can be expressed as:

$p_{q}=\frac{v^{2}}{x} \sin \delta+\frac{v}{x} v_{q} \cos \left(\frac{\delta}{2}\right)$

The SC, therefore the power flow can increase, or decrease the procedure, simply by reversing the polarity of the inserted voltage. The reversed voltage $\left(180^{\circ}\right.$ phase shifted $)$ directly adds to the reactive part of the voltage drop of thetransmission line and this was increased the reactive line impedance. Also, if the SC voltage output is made larger than the voltage across the uncompensated impedance line by the between sending end and receiving end, this main if: $\left|\mathrm{V}_{\mathrm{q}}\right|>\left|\mathrm{V}_{\mathrm{a}}-\mathrm{V}_{\mathrm{b}}\right|$, then power flow in the line can reverse [11]. The stable operation of the power system in both negative and positive of power flows through transmission line can be observed that the SC has an fast response time and also that the transition from negative to positive of power flow and vice versa through crossing zero voltage injection is perfectly continuous and smooth [12].
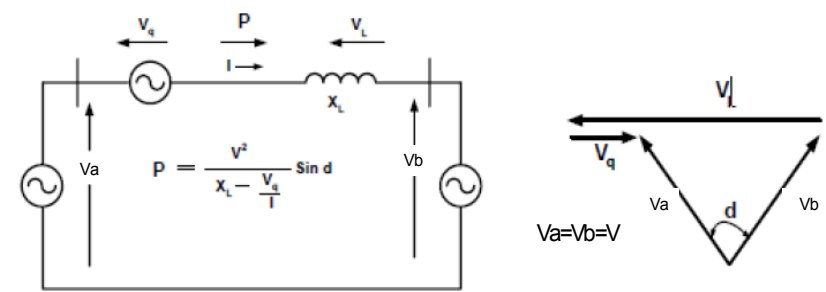

Figure 3 Two-machine power system with Series Compensator SC and the voltage phasor diagram

\section{ACTIVE AND REACTIVE POWER MEASURING}

D-q theory was used to measure the active and reactive power. The advantage of this theory is based on timedomain, and it is valid for transient state or steady-state operation, also for generic waveforms of current and voltage power system, also sutabe for controlling active filters in realtime [12]. Another characteristic of $d-q$ theory is the simplicity calculations, that include algebraic calculations exception that the need of separating the mean value and alternated value when calculated the power components [13]. In this theory transformation known "park transformation" to transform a stationary coordinates a-b-c "reference system" to rotating coordinates d-q. The transform applied in time-domain for voltages and currents in the natural frame (i.e. $v_{a}, v_{b}, v_{c}$ and $i_{a}, i_{b}, i_{c}$ ) are as follow:

$$
\begin{aligned}
& {\left[\begin{array}{l}
v_{d} \\
v_{q} \\
v_{0}
\end{array}\right]=\frac{2}{3}\left[\begin{array}{ccc}
\cos (\varnothing) & \cos \left(\varnothing-\frac{2 \pi}{3}\right) & \cos \left(\varnothing+\frac{2 \pi}{3}\right) \\
-\sin (\varnothing) & -\sin \left(\varnothing-\frac{2 \pi}{3}\right) & -\sin \left(\varnothing+\frac{2 \pi}{3}\right) \\
\frac{1}{2} & \frac{1}{2} & \frac{1}{2}
\end{array}\right]\left[\begin{array}{l}
v_{a} \\
v_{b} \\
v_{c}
\end{array}\right]} \\
& {\left[\begin{array}{l}
i_{d} \\
i_{q} \\
i_{0}
\end{array}\right]=\frac{2}{3}\left[\begin{array}{ccc}
\cos (\varnothing) & \cos \left(\varnothing-\frac{2 \pi}{3}\right) & \cos \left(\varnothing+\frac{2 \pi}{3}\right) \\
-\sin (\varnothing) & -\sin \left(\varnothing-\frac{2 \pi}{3}\right) & -\sin \left(\varnothing+\frac{2 \pi}{3}\right) \\
\frac{1}{2} & \frac{1}{2} & \frac{1}{2}
\end{array}\right]\left[\begin{array}{l}
i_{a} \\
i_{b} \\
i_{c}
\end{array}\right]}
\end{aligned}
$$

Where $\varnothing$ is the angle between the fixed and rotating coordinate system with time, $\theta$ is the phase shift between line current and the voltage. Then the compensated reactive and active power calculated by:

$p=V_{d} I_{d}+V_{q} I_{q}$

$q=V_{d} I_{q}-V_{q} I_{d}$

\section{CONTROL SCHEME OF SC COMPENSATOR}

The control of compensator system is shown in Figure 4. The control system consists of transmission line between two generating machine units with load. The SC is provided with a DC source that helps in absorbing or feeding the reactive and active power from or to the system. The line current and voltage for three phase are measured then active $\mathrm{P}$ and reactive $\mathrm{Q}$ powers are calculated by using park transformations eq 10 and 11 . The parameters $\mathrm{P}$ and $\mathrm{Q}$ work as feed back input to closed loop control system.

The references active power $p_{\text {ref }}$ and reactive power $q_{\text {ref }}$ are compared with thefeed back signal $\mathrm{P}$ and $\mathrm{q}$ respectively and then generate "error signals" Error $_{p}$ and Error ${ }_{q}$. These signals are processed in the controller:

$\operatorname{Erorr}_{P}=P_{\text {ref }}-P$
$\operatorname{Erorr}_{q}=q_{\text {ref }}-q$ 


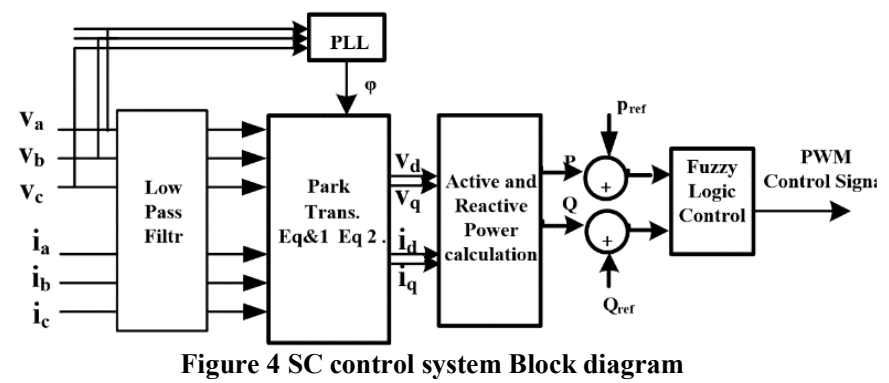

IV. FUZZY LOGIC CONTROL

Fuzzy Logic control FLC systems are appropriate for approximate reasoning or uncertain systems, especially with the system of mathematical model which is difficult to derive it. FLCs are an important in many practical applications. In fuzzy logic control there are many type of fuzzy inference mechanisms and Takagi-Sugeno TS is chosen in this control. To tune the membership functions of control the artificial neural network ANN will be used in this study for fuzzy like PI controller. The TS fuzzy type has non-linear variable gain of controller. And this produces variations of the gain of the controller. Arbitrary choosing of these parameters may lead to instability system or an adequate response [14].

By using Neuro-Fuzzy control a better response can be achieved. Employing ANN learning algorithm to adapt the fuzzy parameters and rules. The controller is combine the adaptive learning capabilities of the ANN with fuzzy specific approach, This control can be trained without a great knowledge of expert as required for the mamdani FLC [15]. In this type the fuzzy rule can be reduced. The membership functions of the input and output parameters are to be specified during the training. In this study the FLC designed consists of five layers. The aim of using the adaptive learning algorithm is to correct the membership functions factors so that the output of NFC matching the training data better than other types.

To adjust the input and output membership functions parameters the learning algorithm is used so that the FLC output get best matching of the training data, and to identify the network parameters, a hybrid learning strategy (Lease Squares Estimate) and (Gradient Descent) are applied. The Gradient Descent method updates the previous parameters of membership function. In this paper, the input universe of discourse is split into five membership functions trapezoidal type with $50 \%$ overlapping, therefore. Two control inputs, with twenty five control rule result linear functions required to be determined as shown in Figure $5 \mathrm{a}$ and $\mathrm{b}$.

Two sets of data are to be generated for tuning rules of the TS using ANFIS,. The two inputs data are vectors of the error signal " $\mathrm{E}_{\mathrm{p}}$ and $\mathrm{E}_{\mathrm{q}}$ ", while the output is the modulation index (m). Figure6 shows the validation test of Fuzzy logic system.

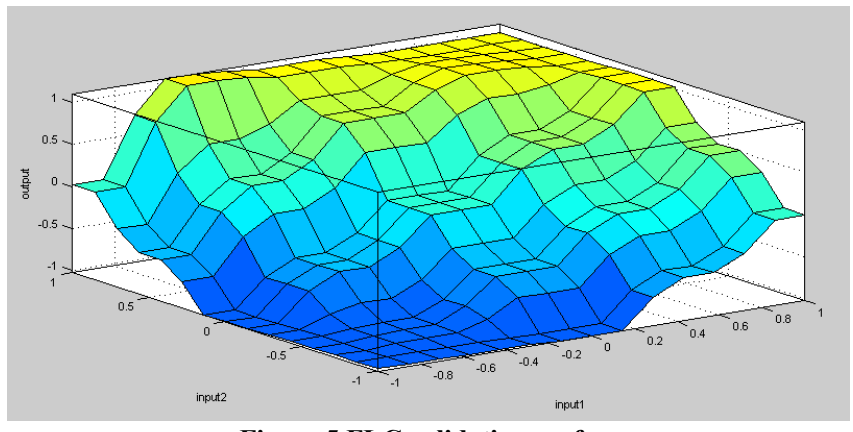

Figure 5 FLC validation surface

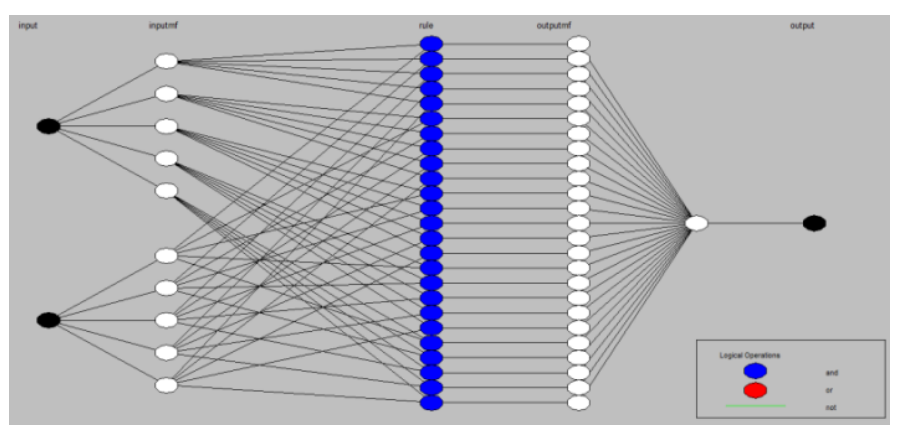

Figure 6 FLC structure

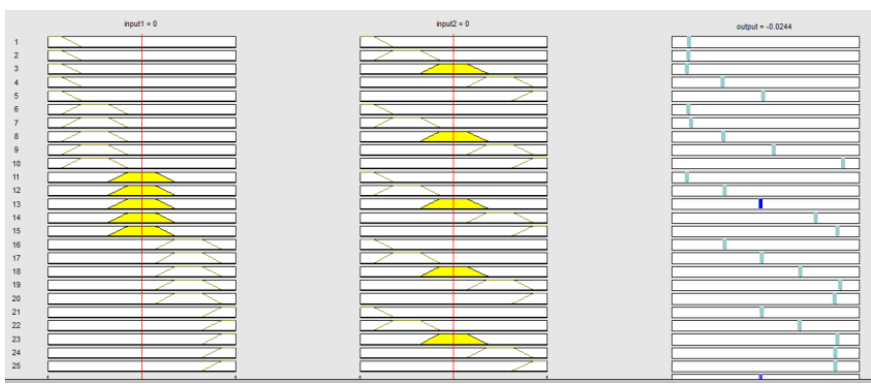

Figure 7 Fuzzy logic rules

the control inputs are split into five membership function with overlapping of $50 \%$. Therefore, 25 -control rules for these two controller inputs, consequently linear functions can be determined.

\section{SIMULATION STUDY}

In this study the model of power system consists of feeder with two parallel branches as shown in figure 8 . The SC system installed in branch 2 at busbar2 (BB2) to control the impedance of BB2. The simulation test start by changing the load and measure the current in each branch and the total current and without compensation.

The compensation done by inject controllable voltage that was made vertical to the line current and this will control the reactive part of line impedance. Firstly to validate the SC, the test done by injected cotrolable in series with the line for one step change as shown in figure 9 at $\mathrm{t}=0.18$ second the output voltage of the SC increased from 0 to its maximum value, and this decreased the overall $\mathrm{BB} 2$ impedance and increased the line current in BB2 as shown in figure 10 a and $b$ respectively, the total voltage across the line impedance with SC is shown in figure 11.

To validate the SC for different operating points, two step changes were applied, first change at $\mathrm{t}=0.11$ second and 
second change at $\mathrm{t}=0.275$ second the resuls shown in figure 12.

The results showed the Depends on the controllable compensated voltage the line current in BB2 branch is increased by $0.5 \mathrm{pu}$ at $\mathrm{t}=0.11$ second to its desired value and
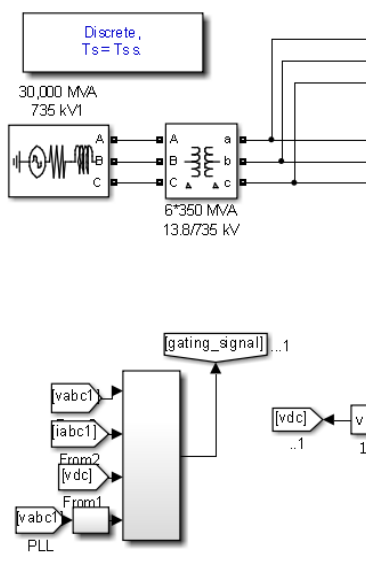

next step increased to maximum value at $\mathrm{t}=0.275$ second in this point the feeder current divided equally between the two branches as shown in figure $13 \mathrm{a}$ and $\mathrm{b}$ respectively.

Power Flow Control in Parallel TLs

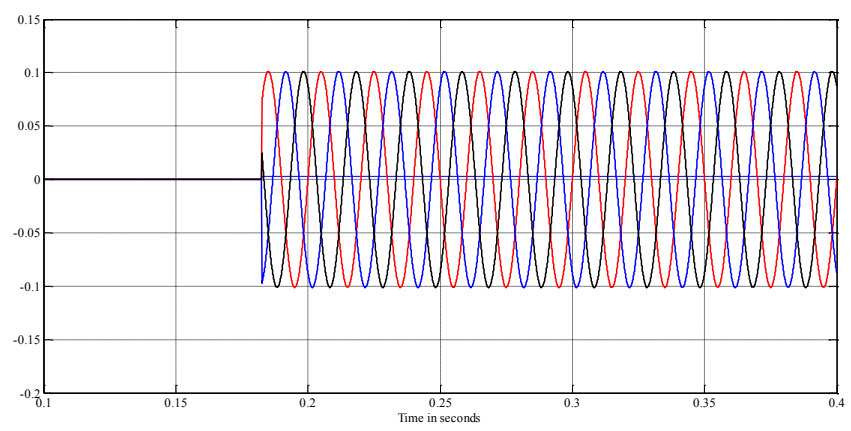

Figure 9 The compensation voltage

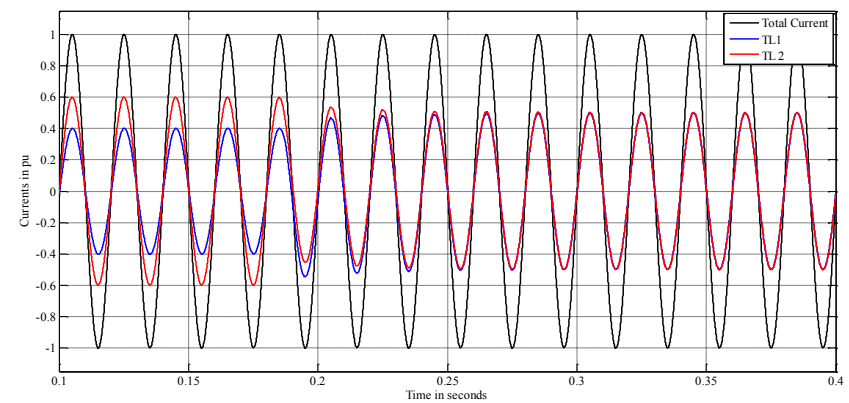

a The waveforms of the branchcurrents and the feeder current

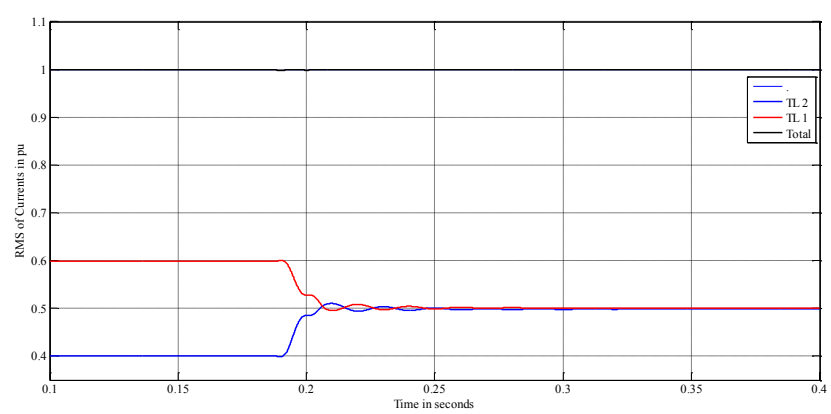

b The rms of the branch currents and feeder

Figure 10 Line currents before and after SC action

To validate the control system, figure 14 shows the results of step change in the active power.
The results shows the system response to load step change, the result is clear that the use of FLC controller better than conventional PI in a smoother response and faster reaches the steady state.

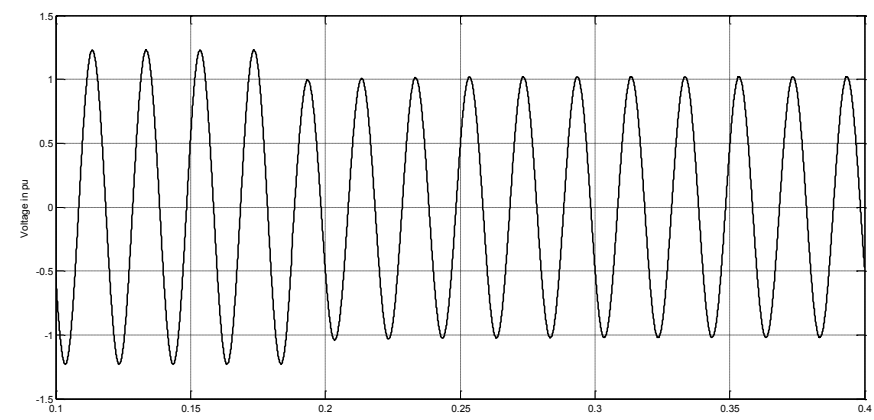

Figure 11 Total voltage across the line impedance with SC

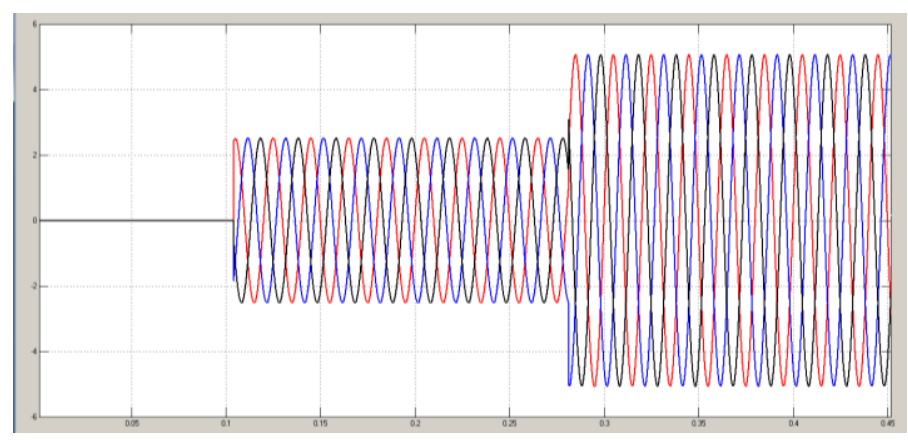

Figure 12 The SC output voltage

\section{CONCLUSION}

In this paper, TS type of FLC is used to control the series compensator. Adaptive Neuro-Fuzzy Inference is employed for tuning algorithm (off-line). Mamdani fuzzy-like-PI rules are used to initiate the tuning control process. The advantage of small computation time implemented the controller in real time. The proposed scheme of controller has been applied to control SC that used to regulate the power 
transmitted through parallel transmission system by controlling the line impedance. The experimental and simulation results show that the FLC controller provide faster and smoother than conventional controller for the SC. Also fast measurement too was used (d-q theory) for measuring the reactive and active power respectivily.

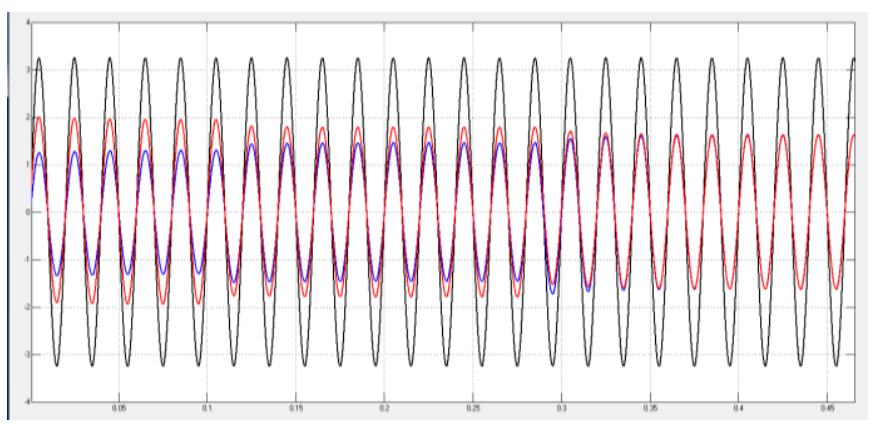

a The amplitude of currents in $\mathrm{BB} 1, \mathrm{BB} 2$ and the total current

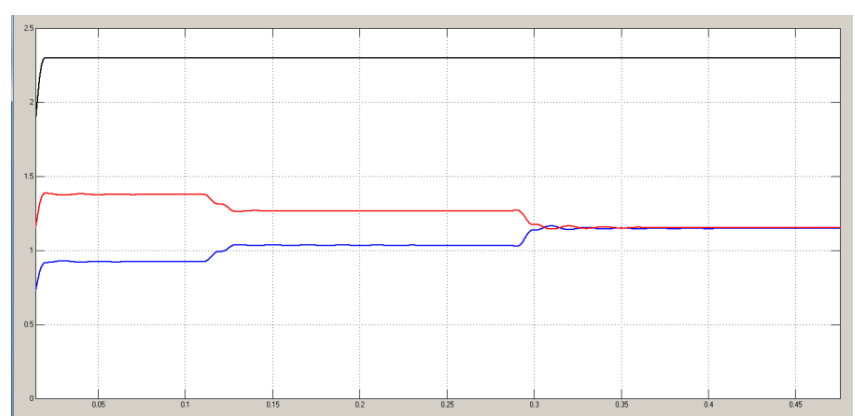

b The rms values of the currents Figure 13 The currents before and after compensation

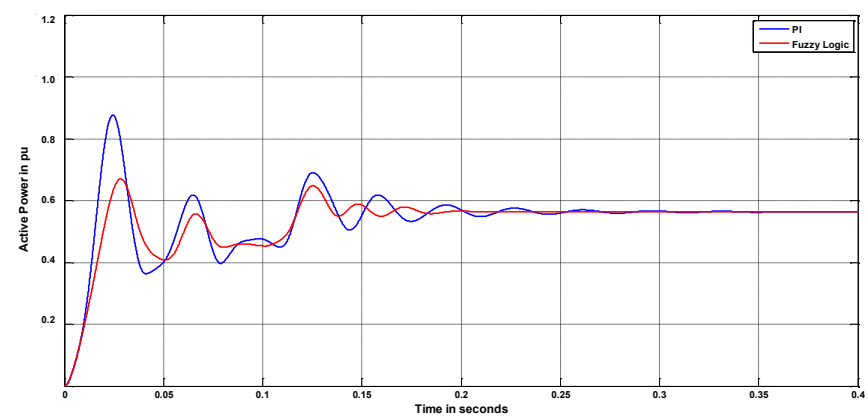

Figure 14 Step change in active power

\section{REFERENCES}

[1] L. Gyugyi, "Dynamic compensation of ac transmission lines by solidstate synchronous voltage sources", IEEE Trans. Power Delv., vol. 9, no. 2 , pp. 904-911, 1994.

[2] L. Gyugyi, C. D. Schauder, and K. K. Sen, "Static synchronous series compensator: a solid state approach to the series compensation of transmission lines", IEEE Trans. Power Delv., vol. 12, pp. 406-417, 1997.

[3] D. Murali and et al, "Comparison of FACTS Devices for Power System Stability Enhancement", International Journal of Computer Applications, vol.8,no.4, pp. 30-35, 2010 .
[4] Chintan R Patel, Sanjay N Patel," Static Synchronous Series Compensator (SSSC): An approach for reactive power compensation for the transmission system", National Conference on Recent Trends in Engineering \& Technology, B.V.M. Engg College, .V.Nagar, Gujarat, India, 13-14 May 2011.

[5] Mostafa Sahraei-Ardakani and Kory W. Hedman, "A Fast LP Approach for Enhanced Utilization of Variable Impedance Based FACTS Devices", IEEE Transactions on Power Systems, Vol. 31, Issue: 3, pp. 2204 - 2213, 2016

[6] Hilmi Zenk and Adem Sefa Akpinar, "PI, PID and fuzzy logic controlled SSSC connected to a power transmission line, voltage control performance comparison", Fourth International of Power Engineering, Energy and Electrical Drives (POWERENG), pp. 1493-1497, 2013.

[7] C. Anitha; P. Arul, " Enhancement of voltage stability in transmission system using SSSC", International Conference on Circuit, Power and Computing Technologies (ICCPCT), pp. $30-33,2014$

[8] M. Abbasi; B. Tousi,“ Novel controllers based on instantaneous p-q power theory for transformerless SSSC and STATCOM", IEEE International Conference on Environment and Electrical Engineering and IEEE Industrial and Commercial Power Systems Europe (EEEIC / I\&CPS Europe), 6-9 June, 2017.

[9] Mohammed Y. Suliman and Sinan. M. Bashi, "Fast response SSSC based on instantaneous power theory", International Conference on Electrical, Communication, Computer, Power, and Control Engineering (ICECCPCE), pp. $174-178,2013$.

[10] S . Panda, "Multi-objective evolutionary algorithm for SSSC-based controller design", Electr. Power Syst. Res.,vol.79, no. 6, pp. 937-944, 2009.

[11] DiptiMohanty and et al, "Modelling, simulation and performance analysis of FACTS controller in transmission line" International Journal of Emerging Technology and Advanced Engineering, Vol 3,Issue 5,pp. 428-435, 2013.

[12] Mohammed Y. Suliman and S. M. Bashi," Instantaneous Active and Reactive Power Measuring in Three Phase Power System", 3rd International Scientific Conference of F.T.E, Najaf, Iraq, 20-21 Feb, pp. 926-936, 2013

[13] E H Watanabe and Akagi H, "Instantaneous p-q power theory for control of compensators in micro-grids" IEEE No sinusoidal Currents and Compensation (ISNCC), pp. 17-26, 2010 .

[14] Farrag M. E. A, G. A. Putrus," Design of adaptive neuro-fuzzy inference controller for a transmission system incorporating UPFC", IEEE, Transaction on Power Delivery, vol.27,Issues:1, pp. 53-61,2012

[15] Mohammed Y. Suliman, M. E. Farrag and Sinan Bash,"Design of Fast Real Time Controller for the SSSC Based on Takagi-Sugeno (TS) Adaptive Neuro-Fuzzy Control System", International Conference on Renewable Energies and Power Quality (ICREPQ'14) Cordoba (Spain), 8th to 10th April, Vol.1, No.12, pp. 1025-1030, 2014.

[16] Farrag M. E. A., Putrus G. A. and Ran L., "Artificial Neural Network Based Adaptive Takagi-Sugeno Fuzzy Like 
PI Controller For Optimal UPFC Performance" IEEE 7th

International Conference on Intelligent Engineering

Systems, Assiut, Egypt 4-6 March, pp. 312-316, 2003. 